\title{
Hybrid multi-response optimization of friction stir spot welds: failure load, effective bonded size and flash volume as responses
}

\author{
$\mathrm{O}_{\mathrm{O}} \mathrm{OJO}^{1,2, *}$ and $\mathrm{E} \mathrm{TABAN}^{2,3}$ \\ ${ }^{1}$ The Federal University of Technology Akure, Akure, Ondo State, Nigeria \\ ${ }^{2}$ Kocaeli University, Izmit, Kocaeli, Turkey \\ ${ }^{3}$ Welding Research Education and Training Centre, Kocaeli University, Izmit, Turkey \\ e-mail: ojooladimeji90@yahoo.com
}

MS received 22 June 2017; revised 26 October 2017; accepted 18 November 2017; published online 8 June 2018

\begin{abstract}
Friction stir spot welding (FSSW) is a multi-input multi-response process. Effective multi-response optimization of welds is desirable to create welds with a balance of quality responses. In order to eliminate the subjectivity (uncertainty and engineering judgment) with the existing multi-response Taguchi-based Grey relational analysis, principal component analysis (PCA) was integrated into it. The PCA helps in determining the effective optimal weighting values required for the estimation of Grey relational grade (GRG). As a result, tool rotational speed, plunge depth and dwell time were employed as input parameters while failure load (FL), expelled flash volume (EFV) and effective bonded size (EBS) of conical pin friction stir spot-welded joint of AA2219-O alloy were the chosen output responses. EFV was minimized while FL and EBS of the joints were maximized using this hybrid multi-response approach. From the analysis of variance of GRG and its response graphs, the significant parameters and their levels were obtained. Experimental results confirmed the effectiveness and robustness of this method. In addition, three critical zones were observed on the fracture surfaces of joints, namely, tool impelled unbonded zone, partially bonded zone and effective bonded/nugget zone. The weld nugget failed by circumferential nugget shear mode.
\end{abstract}

Keywords. Friction stir spot welding; effective bonded size; failure load; expelled flash volume; hybrid multiresponse approach; fracture mode.

\section{Introduction}

Friction stir spot welding (FSSW) is an eco-friendly or green solid-state joining process that has the capacity of eliminating the conventional fusion welding problems of low-density alloys like aluminium, copper, titanium, magnesium and even metal matrix composites [1]. As such, the predominant weldability problems of fusion welding of aluminium alloys, such as thermal shrinkages and distortion, weld porosity or internal voids [2-5], alloy segregation, formation of brittle inter-dendritic structure [6], microfissuring and hot cracking [4, 7], evaporation of strengthening or alloying elements [8], solidification stress corrosion and pitting corrosion, can be efficiently reduced or eliminated with the application of FSSW process. Consequently, FSSW has become a desirable and widely accepted fabrication technology that has found its application in industries like automotive, aerospace and aviation, and high-speed train manufacturing [2].

However, the optimization of FSSW system is still an attractive area of focus in the industries. There is a need to

*For correspondence optimize the quality of friction stir spot-welded joints. The quality of welds can be checked or assessed in terms of defects, tensile strength, hardness, microstructure, nugget or bonded size and other joint features. Meanwhile, tool geometry and parameter levels are the notable independent factors that greatly influence the quality of welds [9]. As a result, these factors are usually varied to optimize weld quality in FSSW. There are several modern techniques available for the optimization of FSSW and these techniques can be broadly grouped into two, namely single response optimization approach and multi-response or multi-objective optimization approach. Only one quality characteristic can be optimized at a time with a single response optimization approach while two or more quality characteristics can be combined and optimized with a multi-response optimization approach. Howbeit, robust design of experiment is generally applied in either single response or multi-response optimization of welding processes.

A lot of single response optimization processes have been investigated on weld strengths of alloys such as AA6061-T6 and AA7075-T6 using either the Taguchi method (TM), central composite design (CCD) or response 
surface methodology (RSM) [7, 10-13]. However, the optimal condition of friction stir welding of AA8011-6062 composite was conducted by Elanchezhian et al [14] via TM. Two responses (tensile and impact strengths) were chosen for the analysis by the authors. Due to a single response optimization capability of TM, the parameter combination that produced the optimum tensile strength was different from that of optimum impact strength [14]. Thus, joints with a combination of high tensile strength and high impact strength could not be investigated at a single time. As a result, multi-response optimization method is required to identify joints with optimum combination of the respective quality characteristics or responses. The existing approach that has been employed in examining multi-objective optimization of friction stir welding in literature is based on either Grey relational analysis (GRA) or a combination of GRA and other design approaches. For instance, Kesharwani et al [15] and Kumar and Kumar [16] applied multi-objective optimization of process parameters on dissimilar welding of AA5052-H32/AA5754-H22 and AA6061/AA6082 using a Taguchi-based Grey approach. Also, Palani and Elanchezhian [4] investigated multi-response optimization of process parameters on AA8011 friction stir welded aluminium alloys using RSM-coupled GRA.

However, the issue with the existing GRA or Taguchibased Grey optimization approach is that the weighting factor/value required for the estimation of Grey relational grade (GRG) is usually based on engineering judgment/ assumption or based on the average value of the Grey relational coefficient. Thus, this creates subjectivity in the outcome of the optimized results [17]. As a result, there is a need for a more efficient means of determining the requisite weighting values required for the evaluation of GRG. The application of principal component analysis (PCA) has been identified to be capable of providing the needed optimal weighting values [17]. In fact, the use of PCA in transforming correlated quality responses to uncorrelated components and evaluation of principal components was first introduced into multi-response optimization by Fung and Kang [18] in 2005. As a result, this provided a strong support for the use of PCA in computing weighting values for the formulation of GRG. However, the integration of PCA into Taguchi-Grey-based optimization approach to form hybrid TM-GRA-PCA was proposed and demonstrated on plastic gear production by Mehat et al [17] in 2014. Thus, this hybrid multi-response process is an improved optimization process that is yet to be applied to welding processes like FSSW.

In our previous paper, it was affirmed that conical pin welded joints produced significant volume of flash in friction stir spot welds [19]. Thus, there is a need to minimize the overall expelled flash volume (EFV) of pin-assisted welds without jeopardizing other essential weld qualities. As a result, this paper minimizes weld defect (flash) and maximizes metallurgically bonded region and failure load
(FL) of conical pin welded joint via the use of a hybrid multi-response optimization approach (hybrid TM-GRAPCA) over a selected range of process parameters. Equally, the fracture surfaces of welds were examined to identify critical zones and fracture pattern of welds when subjected to monotonic axial loading condition.

\section{Materials and methods}

Rolled sheets of 1.6-mm thick Alclad AA2219-O aluminium alloy, having ultimate tensile strength, yield strength and elongation of $146 \mathrm{MPa}, 63 \mathrm{MPa}$, and $22.3 \%$, respectively, were employed for this research. Its major chemical compositions include $6.6 \mathrm{wt} \% \mathrm{Cu}, 0.32 \mathrm{wt} \% \mathrm{Mn}$, $0.02 \mathrm{wt} \% \mathrm{Mg}, 0.06 \mathrm{wt} \% \mathrm{Si}, 0.14 \mathrm{wt} \% \mathrm{Fe}$ and $0.06 \mathrm{wt} \% \mathrm{~V}$. The as-received alloy was cut into manageable sizes and cleaned with acetone prior to FSSW. Two plates of the alloy having dimensions of $100 \mathrm{~mm} \times 30 \mathrm{~mm}$ were positioned in overlap configuration to form a lap shear specimen in such a manner that the overlapped area was $30 \mathrm{~mm}$ $\times 30 \mathrm{~mm}$. This geometrical arrangement was utilized for the FSSW process. High-speed tool steel (10-mm diameter) was the selected tool material and a conical pin tool (having pin tip: $6 \mathrm{~mm}$, pin base: $6 \mathrm{~mm}$ and pin height: $2.47 \mathrm{~mm}$ ) was fabricated from it. An adapted CNC milling machine was utilized for the welding process with a selected range of process parameters. After a series of trial experiments, the selected process parameters and their levels employed for this research are highlighted in table 1.

In accordance with TS EN ISO 6892-1 standard, the FLs of the lap shear weld specimens were obtained with the aid of a computer-controlled Zwick tensile machine. The shear specimens were subjected to a constant displacement rate of $0.5 \mathrm{~mm} / \mathrm{s}$ until complete sheets separation. The fracture surfaces of welds subjected to axial loading were examined in a scanning electron microscopy (SEM).

Likewise, the effective bonded size (EBS) of conical pin welds is described as the metallurgically bonded length between the tip of the hook path and the pinhole as illustrated in figure 1. In order to obtain the values of EBS, fracture surface inspection was employed according to figure 2 and the EBS of all welds was measured. The accuracy of this approach was checked through the assessment of two metallographic weld samples. Less than $8 \%$ deviation existed between the obtained EBS from the metallographic weld samples and from that of fracture surfaces. Meanwhile, standard metallographic process was

Table 1. Welding parameters and their levels.

\begin{tabular}{lcccc}
\hline Column & Factors & Level 1 & Level 2 & Level 3 \\
\hline A & Rotational speed (rpm) & 1400 & 1500 & 1600 \\
B & Plunge depth (mm) & 2.90 & 2.92 & 2.95 \\
C & Dwell time (s) & 4 & 5 & 6 \\
\hline
\end{tabular}




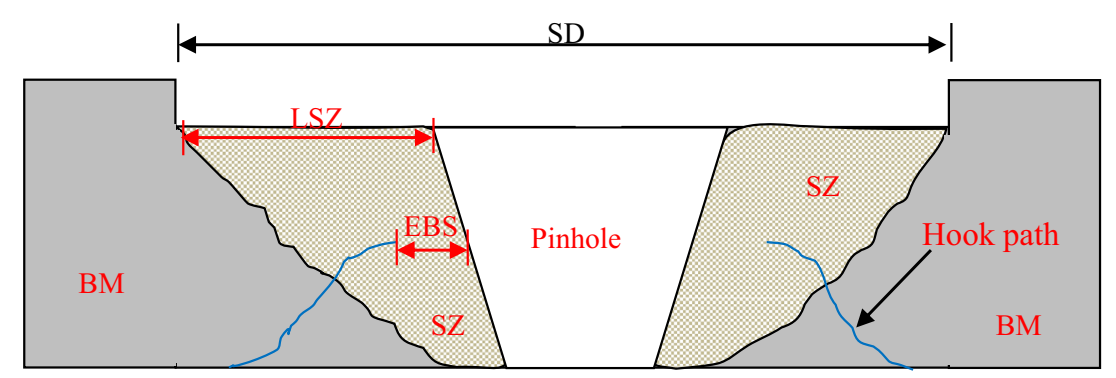

Figure 1. Illustration of effective bonded size of conical pin welded joint. SD—shoulder diameter; LSZ-length of stir zone near the shoulder surface; EBS—effective bonded size; SZ—-stir zone; BM—unaffected base metal.

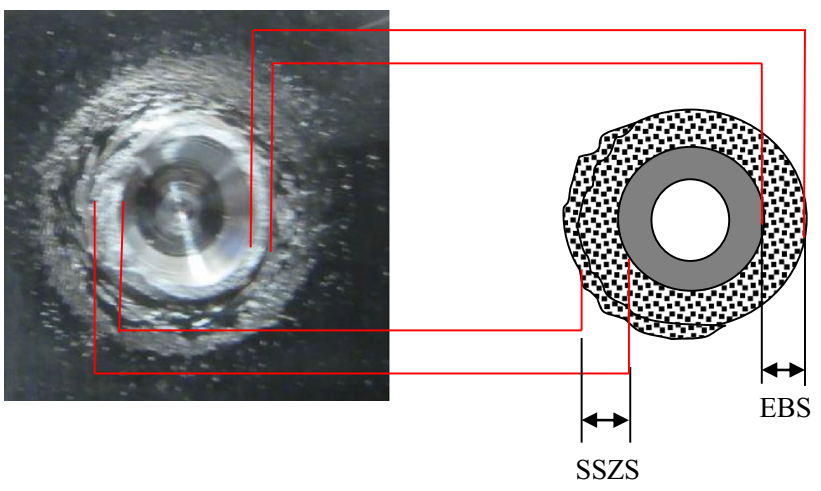

Figure 2. Assessment of bonded size of conical pin welded joint via fracture surface inspection (EBS-effective bonded size; SSZS — sheared stir-zone size (or shearing of the effective bonded size through the region below the hook tip).

employed for the validation of the EBS. The weld crosssectional surfaces were ground in several stages using 1000 and 2400 gr emery papers while 3 and $0.25 \mu \mathrm{m}$ diamond pastes were utilized in polishing the surfaces in an electropolishing unit for $220 \mathrm{~s}$ at $20 \mathrm{~V}$. Subsequently, the specimens were etched in $2 \%$ tetrafluoroboric acid to reveal the EBS of the welds. The prepared metallographic specimens were examined using a ZEISS light optical microscope $(\mathrm{OM})$ in order to ascertain the values of EBS.

The EFV of conical pin welds was computed as described in our previous paper [19] using Eq. (1). The thicknesses and pushed out lengths of ring and serrated flashes of conical pin welded joints were measured with the aid of digital calipers. Due to the variation in the pushed out lengths of serrated flash, an approximated pushed out length was computed as the average of the minimum and maximum push out lengths.

$$
\mathrm{EFV}=\pi\left[L_{\mathrm{f}}^{2}+10 L_{\mathrm{f}}\right] h_{\mathrm{rf}}+\pi\left[\left(2 L_{\mathrm{f}}+10\right) L_{\mathrm{s}}+L_{\mathrm{s}}^{2}\right] h_{\mathrm{sf}}
$$

where $L_{\mathrm{f}}$ is the pushed out length of ring flash, $h_{\mathrm{rf}}$ is the thickness of ring flash, $L_{\mathrm{s}}$ is the approximate pushed out length of serrated flash and $h_{\mathrm{sf}}$ is the thickness of serrated flash. However, the hybrid optimization procedures for the selected quality responses are described in section 2.1.

\subsection{Hybrid optimization of responses}

The hybrid optimization approach combines three processes, which are TM, GRA and PCA in optimizing multiple weld responses. A typical flow chart for the entire hybrid system is shown in figure 3 . The hybrid process commences with TM needed to obtain the requisite quality responses (in $\mathrm{dB}$ ). It is then followed by the first (1st) phase of GRA, which includes normalizing the quality responses (in $\mathrm{dB}$ ) and formulation of Grey relational coefficient (GRC). The intermediate phase (PCA) is followed and the optimal weighting values needed for the multi-response optimization are determined via the PCA. In the final phase of GRA, GRG is obtained and the required optimum parameter levels are obtained. Thus, validation of results is consequently performed.

2.1a TM: The TM helps in reducing the number of experimental runs, and saves time and cost through its experimental approach. However, the Taguchi design method combines the concept of orthogonal arrays and quality loss function in solving several single response problems. Based on the number of welding parameters and levels (see table 1), L9 orthogonal array was designed for the experiment as illustrated in table 2. Since the Taguchi design of experiment employs three categories of quality characteristics or signal-to-noise $(S / N)$ ratio in its approach, appropriate selection of $S / N$ ratio is desirable in order to have efficient analysis. This selection process is usually based on previous knowledge, understanding of the process and expertise [7]. In this research, the EFV needs to be minimized while EBS and FL are to be maximized. As a result, the smaller-the-better $S / N$ ratio and the larger-the-better $S /$ $N$ ratio shown in Eqs. (2) and (3) [7, 18, 20-22] are employed for the analysis of EFV, and EBS and FL, respectively. The obtained $S / N$ ratios of all the weld responses in decibel $(\mathrm{dB})$ are employed for the optimization process. These values are transferred to the next stage (1st phase of GRA) for further analysis.

Smaller-the-better $S / N$ ratio

$$
S / N=-10 \log _{10}\left[\frac{1}{n} \sum_{i=1}^{n} Y_{i}^{2}\right]
$$




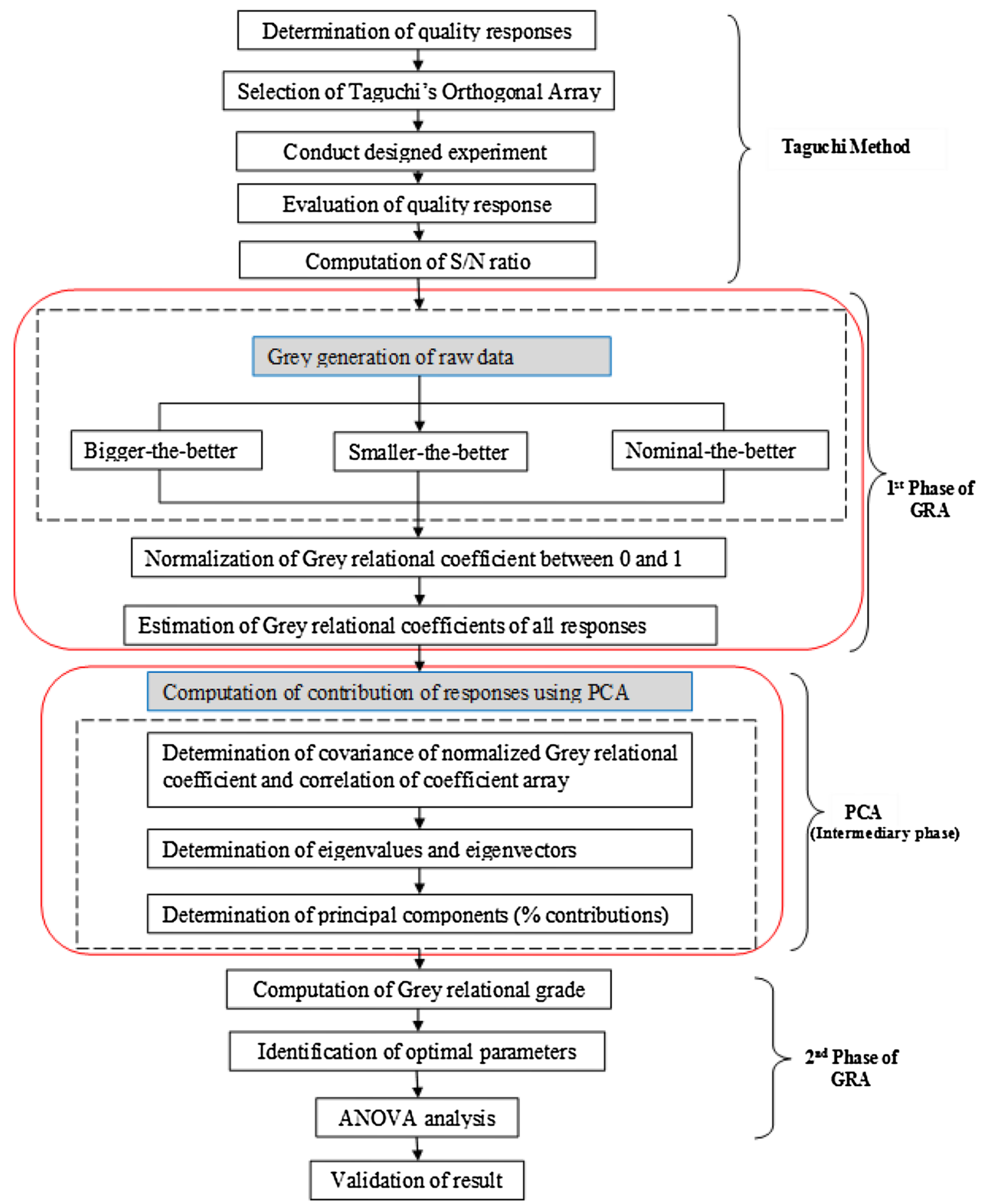

Figure 3. Flow chart of hybrid integration of Taguchi method (TM), Grey relational analysis (GRA) and principal component analysis (PCA).

larger-the-better $S / N$ ratio

$$
S / N=-10 \log _{10}\left[\frac{1}{n} \sum_{i=1}^{n} \frac{1}{Y_{i}^{2}}\right]
$$

where $n$ is the number of measurements in a trial/row and $Y_{i}$ is the measured value/response in a run for $i$ th number of time. 2.1b GRA: GRA is also a statistical tool designed for the investigation of multi-response optimization of processes. However, the main procedures in GRA include Grey relational generation/pre-processing or normalization, computation of Grey relational coefficients and estimation of GRG [23-25]. Consequently, normalization of experimental data is the first step in GRA and the normalized data should be in the range of 0 and 1 . The quality responses (in $\mathrm{dB}$ ) from 
Table 2. Orthogonal array for the experiment.

\begin{tabular}{lccc}
\hline Trial & $\begin{array}{c}A \\
\text { Rotational speed } \\
\text { no. }\end{array}$ & $\begin{array}{c}B \\
\text { Plunge depth } \\
(\mathrm{mm})\end{array}$ & $\begin{array}{c}C \\
\text { Dwell time } \\
(\mathrm{s})\end{array}$ \\
\hline 1 & 1400 & 2.90 & 4 \\
2 & 1400 & 2.92 & 5 \\
3 & 1400 & 2.95 & 6 \\
4 & 1500 & 2.90 & 5 \\
5 & 1500 & 2.92 & 6 \\
6 & 1500 & 2.95 & 4 \\
7 & 1600 & 2.90 & 6 \\
8 & 1600 & 2.92 & 4 \\
9 & 1600 & 2.95 & 5 \\
\hline
\end{tabular}

the TM are normalized using Eqs. (4) and (5) [22, 23, 26]. Based on the target value, Eq. (4) is utilized in normalizing the EBS and FL of welds whereas EFV is normalized using Eq. (5).

The higher the target value-the better (the larger-the better)

$$
x_{i}(k)=\frac{x_{i}^{(\mathrm{q})}(k)-\min \mathrm{x}_{\mathrm{i}}^{(\mathrm{q})}(\mathrm{k})}{\max x_{i}^{(\mathrm{q})}(k)-\min x_{i}^{(\mathrm{q})}(k)}
$$

the smaller the target value-the better (the smaller-the better)

$$
x_{i}(k)=\frac{\max x_{i}^{(\mathrm{q})}(k)-x_{i}^{(\mathrm{q})}(k)}{\max x_{i}^{(\mathrm{q})}(k)-\min x_{i}^{(\mathrm{q})}(k)}
$$

where $x_{i}^{(\mathrm{q})}(k)$ is the measured value of quality characteristic or response, $\max x_{i}^{(\mathrm{q})}(k)$ is the largest or highest value of the quality characteristic and $\min x_{i}^{(\mathrm{q})}(k)$ is the smallest or the least value of the quality characteristic.

Afterwards, the difference sequences for the normalized data are computed using Eq. (6) [29]. Subsequently, the Grey relational coefficients for the responses are then computed. The Grey relational coefficient can be computed through the use of Eq. (7) [4, 16, 23, 26-29]:

$$
\begin{gathered}
\Delta_{\mathrm{o} i}(k)=\left\|x_{\mathrm{o}}(k)-x_{i}(k)\right\| \\
\xi_{i}(k)=\frac{\Delta_{\min }+\Psi \Delta_{\max }}{\Delta_{\mathrm{o} i}(k)+\Psi \Delta_{\max }}
\end{gathered}
$$

where $\Delta_{\mathrm{o} i}(k)$ is the difference sequence, which is defined as the absolute value of the difference between $x_{0}(k)$ and $x_{i}(k)$. Here, $x_{0}(k)$ and $x_{i}(k)$ are the normalized values of a response set (where $x_{\mathrm{o}}(k)$ represents the highest normalized value and $x_{i}(k)$ represents a set of normalized values from $i=0$ to $i=\mathrm{n}$ ). Also, $\Psi$ is the distinguishing or identification coefficient, which is usually set within 0 and 1 . This implies that $0 \leq \Psi \leq 1$. Most studies set $\Psi$ to be equivalent to 0.5 . Also, $\Delta_{\min }$ is the minimum value in the difference sequence and $\Delta_{\max }$ is the maximum value in the difference sequence.

A GRG is a weighted sum of the Grey relational coefficients. It can be computed by either estimating the average of the Grey relational coefficient or by weighted estimation (factoring in the effects of each factor/response into the resultant GRG). Equation (8) is a mathematical expression for finding the mean of the computed Grey relational coefficients, as GRG while Eq. (9) is employed when weighting values of responses are provided for the computation of GRG [4, 17, 30, 31]. In order to eliminate engineering judgment or assumption during the computation of GRG, efficient identification of weighting factors is vital and these optimal weighting factors are determined via the use of PCA (see section 2.1c for the PCA's procedures).

$$
\begin{gathered}
Y_{i}=\frac{1}{n} \sum_{i=1}^{n} \xi_{i}(k) \\
Y_{i}=\sum_{i=1}^{n} w_{k} \xi_{i}(k)
\end{gathered}
$$

where $Y_{i}$ is the computed GRG for $i$ th term, $n$ is the number of responses or quality factor, $w_{k}$ is the normalized weighting value of quality factor $k$ and $\xi_{i}(k)$ is the Grey relational coefficient.

2.1c PCA (computing weighting values needed for GRG): PCA is a powerful statistical multivariate-analytical tool, which was first introduced by Pearson in 1901 and developed independently by Hotelling in 1933. It is a tool for analysing data by reducing the number of dimensions of a data (or dimensionality of a data set) without any significant loss of information [32]. It is simply used for finding a pattern in a data set of high dimension in order to highlight similarities and differences in the data set [33]. Thus, PCA examines variance-covariance among a given set of quality responses. As a result, the contribution of each of the responses/optimally weighted observed variables can be easily evaluated [34]. Thus, the weighting values needed for the estimation of GRG can be obtained through the application of PCA. The requisite PCA procedures needed to obtain the contribution of each quality responses or weighting values include the following.

Data matrix of the observed responses (multi-response array): A matrix of the observed responses is required to commence data reduction in PCA. As a result, the Grey relational coefficient (GRC) of each of the observed responses is required to formulate a data matrix. If the element of the data matrix is denoted as $Y_{i}(k)$, then $i$ is set to vary from 1 to $m$ while $k$ is defined to vary from 1 to $n$ as illustrated in Eq. (10): 


$$
Y_{i}=\left[\begin{array}{ccccccc}
Y_{1}(1) & Y_{1}(2) & Y_{1}(3) & \ldots & \ldots & \ldots & Y_{1}(n) \\
Y_{2}(1) & Y_{2}(2) & Y_{2}(3) & \ldots & \ldots & \ldots & Y_{2}(n) \\
Y_{3}(1) & Y_{3}(2) & Y_{3}(3) & \ldots & \ldots & \ldots & Y_{3}(n) \\
\vdots & \vdots & \vdots & \vdots & \vdots & \vdots & \vdots \\
\vdots & \vdots & \vdots & \vdots & \vdots & \vdots & \vdots \\
Y_{m}(1) & Y_{m}(2) & Y_{m}(3) & \ldots & \ldots & \ldots & Y_{m}(n)
\end{array}\right]
$$

where $Y_{i}$ are the responses, $n$ is the number of columns or the number of responses and $m$ is the number of rows or the number of experiments. As a result, in this hybrid TM-GRA-PCA approach, $Y$ is the Grey relational coefficients of the observed responses (EFV, FL and EBS).

Correlation matrix: According to Mehat et al [17] and Fung and Kang [18], correlation matrix is defined as illustrated in Eq. (11):

$$
R_{k l}=\left[\frac{\operatorname{Cov}\left(Y_{i}(k), Y_{i}(l)\right)}{\sigma_{Y i}(k) \sigma_{Y k}(l)}\right]
$$

where $k$ and $l$ vary from 1 to $n$. Also, the covariances of sequences $Y_{i}(k)$ and $Y_{i}(l)$ are defined as $\operatorname{Cov}\left(Y_{i}(k), Y_{i}(l)\right)$ while the standard deviation of sequences $Y_{i}(k)$ and $Y_{i}(l)$ are defined as $\sigma_{Y i}(k)$ and $\sigma_{Y k}(l)$, respectively.

Evaluation of eigenvalues and eigenvectors: Equation (12) shows the relationship among eigenvalue, eigenvector and correction matrix. With this mathematical expression, the values of unknowns, eigenvalues and eigenvectors can be computed:

$$
[R-\lambda \mathrm{I}] V=0
$$

where $\lambda$ is the eigenvalue, $\mathrm{I}$ is an identity matrix, $V$ is the eigenvector and $R$ is the correlation matrix.

Principal components (contribution of each response): The principal components are determined using Eq. (13) $[17,18]$. Thus, the optimal weighting values of the responses are equivalent to the percentage contributions of the responses.

$$
P_{m i}=\sum_{i=1}^{n} Y_{m}(i) V
$$

where $P_{m i}$ is the principal component $\left(P_{m 1}, P_{m 2}\right.$ and $P_{m 3}$ are the 1st, 2nd and 3rd principal component, respectively). Basically, the first principal component accounts for most variance in the data [18].

\section{Results and discussion}

\subsection{Responses}

Figure 4 shows the macrograph of a conical pin welded joint, the inherent hook defect and the grain distribution across the resultant weld zones. Dynamically recrystallized

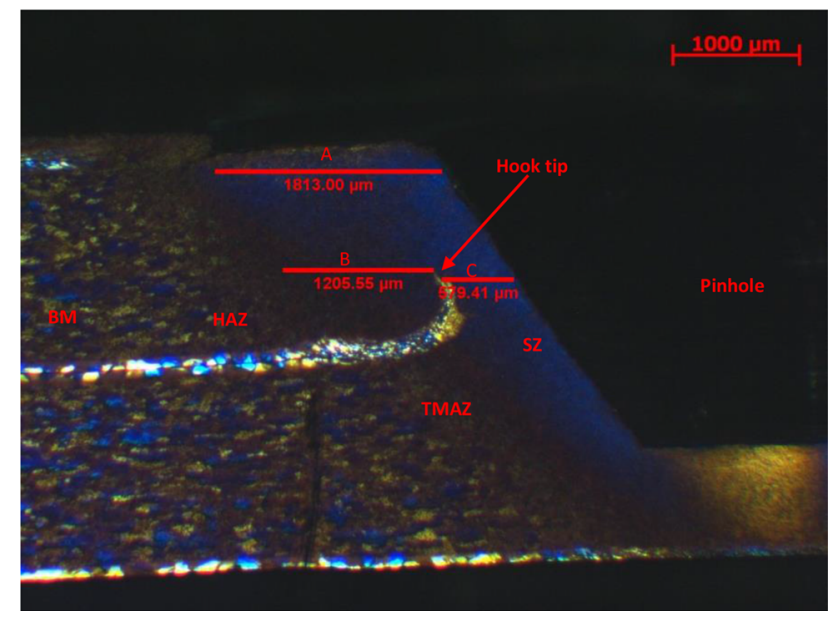

Figure 4. Macrograph showing the weld stir zones: (a) " $A$ " is the stir zone, (b) " $\mathrm{B}$ " is the ineffective stir zone and (c) " $\mathrm{C}$ " is the effective bonded size (EBS) (BM-base metal; HAZ-heataffected zone; TMAZ - thermo-mechanically affected zone; SZstir zone).

grains (refined grain structure) exist in the region adjacent to the pinhole while the base metal has large and elongated grains compared with the grain sizes of the heat-affected zones and thermo-mechanically affected zones. Equally, the redistributed Alclad layers are pushed upwards from the faying region of the weld towards the pin periphery (into the stir zone) to form a hook path or defect. Thus, the formation of hook is chiefly attributed to material flow around the plunging pin length (upward flow of lower sheet material as the tool plunges). Consequently, the presence of inevitable hook divides the resultant stir zone into two sections, namely ineffective stir zone ("B") and EBS ("C") as indicated in figure 4.

As a result, the obtained FL, EFV and EBS of welds according to the designed experiment (see table 2) are provided in table 3 . Based on the obtained results, variation of welding parameters obviously influences the resultant weld responses. In our previous paper [19], the effects of welding parameters on EFV were provided in detail; tool rotational speed and plunge depth had the dominant influences on the expulsion of flash. Thus, the roles of welding parameters on FL and EBS of conical pin welded joints are examined in this paper via analysis of variance (ANOVA) as indicated in tables 4 and 5, respectively. All the examined welding parameters have significant effects on both FL and EBS. However, tool rotational speed has the most dominant effect on FL while the percentage contributions of tool rotational speed, plunge depth and dwell time on FL are 53.47\%, 35.12\%, and $10.64 \%$, respectively. On the other hand, plunge depth has the largest effect on the EBS while the percentage contributions of tool rotational speed, plunge depth and dwell time on EBS are $22.98 \%, 42.68 \%$ and $27.68 \%$, respectively. 
Table 3. Responses of conical pin welded joints.

\begin{tabular}{lccc}
\hline $\begin{array}{l}\text { Exp. } \\
\text { no. }\end{array}$ & $\begin{array}{c}\text { Failure } \\
\text { load }(\mathrm{N})\end{array}$ & $\begin{array}{c}\text { Expelled flash } \\
\text { volume }\left(\mathrm{mm}^{3}\right)\end{array}$ & $\begin{array}{c}\text { Effective bonded } \\
\text { size }(\mathrm{mm})\end{array}$ \\
\hline 1 & 2128.6 & 22.76 & 0.63 \\
2 & 1928.1 & 23.73 & 0.57 \\
3 & 2106.4 & 32.54 & 0.62 \\
4 & 1945.4 & 21.83 & 0.62 \\
5 & 1787.9 & 20.94 & 0.57 \\
6 & 1720.7 & 30.51 & 0.52 \\
7 & 1960.3 & 16.21 & 0.60 \\
8 & 1618.1 & 19.47 & 0.45 \\
9 & 1796.1 & 23.57 & 0.58 \\
\hline
\end{tabular}

The characteristic/parameter effects on the responses such as FL have been reported in literature [2, 19]. Increase in tool rotational speed generally increases the frictional and deformational heat input during FSSW and this induces thermal softening, reduced viscosity and increased flowability within the weld nugget. Consequently, the resultant weld nugget, FL, EBS and EFV are usually impaired as tool rotational speed increases. On the other hand, an increase in plunge depth increases the upward flow of material of the lower plate; this facilitates an increase in the growth of hook curve into the stir zone. Thus, the EFV, EBS and FL are negatively affected as the plunge depth of the welding tool into the workpiece set-up increases. Dwell time has no significant effect on EFV [19] while the resultant FL and EBS are influenced by dwell time (with percentage contributions of $10.64 \%$ and $27.53 \%$, respectively). Nevertheless, the parameter effects on the combined weld responses are the focus of this research and they are investigated via ANOVA of GRGs in section 3.2f.

\subsection{Hybrid optimization}

3.2a $S / N$ ratio of responses (TM): The quality loss values (in $\mathrm{dB}$ ) for each of the responses, FL, EFV and EBS, were computed and are shown in table 6 . The larger-the-better $S / N$ ratio as expressed in Eq. (3) was utilized in computing the quality loss values of FL and that of EBS. However, the smaller-thebetter $S / N$ ratio illustrated in Eq. (2) was employed in estimating the quality loss values ( $S / N$ ratio) of EFV.

$3.2 \mathrm{~b}$ Grey generation/pre-processing of data $\left(I^{\text {st }}\right.$ phase of $G R A$ ): Normalization of the quality loss values was computed according to Eqs. (4) and (5) for FL and EBS and EFV, respectively. The normalization process reduced the respective $S / N$ ratio's values to be between 0 and 1 as shown in table 7.

Prior to the computation of Grey relational coefficients, the deviation sequences $\Delta_{o i}(k)$ as illustrated in Eq. (6) were computed and are shown in table 8 . Consequently, the maximum and minimum values of the deviation sequences were utilized in computing the Grey relational coefficients of each of the responses and are shown in table 9. The value of the distinguishing or identification coefficient of Eq. (7) was set as 0.5 for the estimation of the entire Grey relational coefficients $\xi_{i}(k)$.

$3.2 \mathrm{c}$ PCA (estimation of weighting values/percentage contribution)_intermediary phase: PCA is primarily inculcated into this optimization process in order to eliminate the subjectivity of results brought about by the use of engineering judgment or assumption in the existing multi-objective optimization approaches like Taguchi-Grey-based optimization technique. As a result, to introduce the contribution of each of the responses into the GRA, PCA was

Table 4. ANOVA of failure load (FL).

\begin{tabular}{lccccccc}
\hline Source & DF & Seq SS & Adj SS & Adj MS & $F$-value & $P$-value & Contribution $(\%)$ \\
\hline Rotational speed & 2 & 125670 & 125670 & 62835.2 & 69.68 & 0.014 & 53.47 \\
Plunge depth & 2 & 82540 & 82540 & 41270.1 & 45.76 & 0.021 & 35.12 \\
Dwell time & 2 & 25004 & 25004 & 12501.9 & 13.86 & 0.067 & 10.64 \\
Error & 2 & 1804 & 1804 & 901.8 & & & \\
Total & 8 & 235018 & & & & & \\
\hline
\end{tabular}

$S=30.0298 ; R^{2}=99.23 \%$.

Table 5. ANOVA of effective bonded size (EBS).

\begin{tabular}{lccccccc}
\hline Source & DF & Seq SS & Adj SS & Adj MS & $F$-value & $P$-value & Contribution $(\%)$ \\
\hline Rotational speed & 2 & 0.006067 & 0.006067 & 0.003033 & 3.37 & 0.229 & 22.98 \\
Plunge depth & 2 & 0.011267 & 0.011267 & 0.005633 & 6.26 & 0.138 & 42.68 \\
Dwell time & 2 & 0.007267 & 0.007267 & 0.003633 & 4.04 & 0.138 & 27.53 \\
Error & 2 & 0.001800 & 0.001800 & 0.000900 & & & \\
Total & 8 & 0.026400 & & & & \\
\hline
\end{tabular}

$S=0.03 ; R^{2}=93.18 \%$. 
Table 6. Signal to noise ratio of responses.

\begin{tabular}{lccc}
\hline $\begin{array}{l}\text { Exp. } \\
\text { no. }\end{array}$ & $\begin{array}{c}\text { Failure load } \\
(\mathrm{dB})\end{array}$ & $\begin{array}{c}\text { Expelled flash } \\
\text { volume }(\mathrm{dB})\end{array}$ & $\begin{array}{c}\text { Effective bonded } \\
\text { size }(\mathrm{dB})\end{array}$ \\
\hline 1 & 66.562 & -27.143 & -4.013 \\
2 & 65.703 & -27.506 & -4.883 \\
3 & 66.471 & -30.248 & -4.152 \\
4 & 65.780 & -26.781 & -4.152 \\
5 & 65.047 & -26.420 & -4.883 \\
6 & 64.714 & -29.689 & -5.680 \\
7 & 65.847 & -24.196 & -4.437 \\
8 & 64.180 & -25.787 & -6.936 \\
9 & 65.087 & -27.447 & -4.731 \\
\hline
\end{tabular}

Table 7. Normalization or pre-processing of data (Grey generation).

\begin{tabular}{lccc}
\hline $\begin{array}{l}\text { Exp. } \\
\text { no. }\end{array}$ & $\begin{array}{c}\text { Failure } \\
\text { load }\end{array}$ & $\begin{array}{c}\text { Expelled flash } \\
\text { volume }\end{array}$ & $\begin{array}{c}\text { Effective bonded } \\
\text { size }\end{array}$ \\
\hline 1 & 1.0000 & 0.4869 & 1.0000 \\
2 & 0.6394 & 0.5469 & 0.7024 \\
3 & 0.9618 & 1.0000 & 0.9524 \\
4 & 0.6717 & 0.4271 & 0.9524 \\
5 & 0.3640 & 0.3675 & 0.7024 \\
6 & 0.2242 & 0.9076 & 0.4297 \\
7 & 0.6998 & 0.0000 & 0.8549 \\
8 & 0.0000 & 0.2629 & 0.0000 \\
9 & 0.3808 & 0.5372 & 0.7544 \\
\hline
\end{tabular}

Table 8. Computed deviation sequences.

\begin{tabular}{lccc}
\hline $\begin{array}{l}\text { Deviation } \\
\text { trial no. }\end{array}$ & $\begin{array}{c}\text { Failure load } \\
\left(\Delta_{01}(k)\right)\end{array}$ & $\begin{array}{c}\text { Expelled flash } \\
\text { volume }\left(\Delta_{02}(k)\right)\end{array}$ & $\begin{array}{c}\text { Effective bonded } \\
\text { size }\left(\Delta_{03}(k)\right)\end{array}$ \\
$\begin{array}{l}\text { Ideal } \\
\text { sequence }\end{array}$ & 1 & 1 & 1 \\
\hline 1 & 0.0000 & 0.5131 & 0.0000 \\
2 & 0.3606 & 0.4531 & 0.2976 \\
3 & 0.0382 & 0.0000 & 0.0476 \\
4 & 0.3283 & 0.5729 & 0.0476 \\
5 & 0.6360 & 0.6325 & 0.2976 \\
6 & 0.7758 & 0.0924 & 0.5703 \\
7 & 0.3002 & 1.0000 & 0.1451 \\
8 & 1.0000 & 0.7371 & 1.0000 \\
9 & 0.6192 & 0.4628 & 0.2456 \\
\hline
\end{tabular}

employed to compute the weighting factor of responses by following the steps itemized in section 2.1c. Thus, the computed Grey relational coefficient in table 9 was utilized as the requisite data matrix for the PCA analysis. From the data matrix, the correlation matrix was evaluated and substituted into Eq. (12) to compute the eigenvalues and eigenvectors. The evaluated eigenvalues are shown in table 10. The corresponding eigenvectors of each of the eigenvalues are provided in table 11 .
Table 9. Grey relational coefficients of responses.

\begin{tabular}{lccc}
\hline $\begin{array}{l}\text { Deviation } \\
\text { trial no. }\end{array}$ & $\begin{array}{c}\text { Failure load } \\
\left(\xi_{1}(k)\right)\end{array}$ & $\begin{array}{c}\text { Expelled flash } \\
\text { volume }\left(\xi_{2}(k)\right)\end{array}$ & $\begin{array}{c}\text { Effective bonded } \\
\text { size }\left(\xi_{3}(k)\right)\end{array}$ \\
$\begin{array}{l}\text { seal } \\
\text { sequence }\end{array}$ & 1 & 1 & 1 \\
\hline 1 & 1.0000 & 0.4936 & 1.0000 \\
2 & 0.5810 & 0.5246 & 0.6268 \\
3 & 0.9290 & 1.0000 & 0.9132 \\
4 & 0.6036 & 0.4660 & 0.9132 \\
5 & 0.4401 & 0.4415 & 0.6268 \\
6 & 0.3919 & 0.8441 & 0.4672 \\
7 & 0.6249 & 0.3333 & 0.7751 \\
8 & 0.3333 & 0.4042 & 0.3333 \\
9 & 0.4467 & 0.5193 & 0.6706 \\
\hline
\end{tabular}

Table 10. Eigenvalues and variability of principal components.

\begin{tabular}{lcc}
\hline Principal component & Eigenvalue & Variability (\%) \\
\hline Failure load (FL) & 1.9578 & 65.2584 \\
Expelled flash volume (EFV) & 0.9364 & 31.2134 \\
Effective bonded size (EBS) & 0.1058 & 3.5282 \\
\hline
\end{tabular}

Table 11. Eigenvectors for the principal components.

\begin{tabular}{lccc}
\hline & $\begin{array}{c}\text { First } \\
\text { principal } \\
\text { component }\end{array}$ & $\begin{array}{c}\text { Second } \\
\text { principal } \\
\text { component }\end{array}$ & $\begin{array}{c}\text { Third } \\
\text { principal } \\
\text { component }\end{array}$ \\
\hline $\begin{array}{c}\text { Failure load } \\
\text { (FL) }\end{array}$ & 0.6922 & -0.0908 & 0.7160 \\
$\begin{array}{c}\text { Expelled flash } \\
\text { volume } \\
\text { (EFV) }\end{array}$ & 0.2873 & 0.9447 & -0.1579 \\
$\begin{array}{c}\text { Effective } \\
\text { bonded size } \\
\text { (EBS) }\end{array}$ & 0.6621 & -0.3150 & -0.6800 \\
\hline
\end{tabular}

The variance contribution of the first principal component of the three responses is about $65.26 \%$. This variance contribution is considered to be very high. As a result, the square of the respective eigenvectors is computed as the contribution of each of the responses. The evaluated contributions of the responses are shown in table 12. These contributions are the optimal weighting values for the responses. As a result, the weighting values of $\mathrm{FL}\left(\mathrm{w}_{1}\right)$, EFV $\left(\mathrm{w}_{2}\right)$ and EBS $\left(\mathrm{w}_{3}\right)$ of the welded joints are 0.4791, 0.0826 and 0.4383 , respectively.

3.2d Computation of GRG ( $2^{\text {nd }}$ phase of GRA): The obtained weighting values of the responses (see table 12) 
Table 12. Contribution of each of the responses.

\begin{tabular}{lc}
\hline Responses & Contribution \\
\hline FL & 0.4791 \\
EFV & 0.0826 \\
Effective nugget size & 0.4383 \\
\hline
\end{tabular}

Table 13. Grey relational grade and its order.

\begin{tabular}{lcc}
\hline $\begin{array}{l}\text { Trial no. } \\
\text { Ideal sequence }\end{array}$ & Grey relational grade & $\begin{array}{c}\text { Order } \\
1\end{array}$ \\
\hline 1 & 0.95817 & 1 \\
2 & 0.59643 & 5 \\
3 & 0.92793 & 2 \\
4 & 0.72794 & 3 \\
5 & 0.52208 & 7 \\
6 & 0.46224 & 8 \\
7 & 0.66665 & 4 \\
8 & 0.33918 & 9 \\
9 & 0.55084 & 6 \\
\hline
\end{tabular}

from the PCA together with the Grey relational coefficient in table 9 are employed in computing the GRG according to Eq. (10). Thus, the computed GRGs for the multi-response optimization process are shown in table 13.

3.2e Identification of optimal parameters: Similarly, the comparison of the multi-response's GRGs with the ideal or reference sequence (unity) is basically used to identify the best parameter combination and to also provide the order of significance of each parameter combination. The largest GRG (closest to unity) is considered to give the best combination of quality responses and process parameters. Based on this notion, experimental trial number 1 (see table 13) has the largest GRG (0.95817) and it is adjudged to produce the best combination of process parameters (among the designed experimental set) as well as responses. For this parameter combination, the volume of expelled flash is minimized while the other responses, FL and EBS, are maximized.

The optimal combination of the process parameters (rotational speed, plunge depth and dwell time) that produces the best combination of the quality characteristics is evaluated through the consideration of GRG and the use of main effect analysis. The main effect plot of the GRGs is shown in figure 5 . Thus, based on the graphical illustration of the main effect plot, the optimal combination of the process parameters is obtained for the parameter combination of $1400 \mathrm{rpm}, 2.90 \mathrm{~mm}$ and $6 \mathrm{~s}$ (or A1, B1 and C3). However, the influence of welding parameters on the combined weld responses is examined via analysis of variance (see section 3.2f).

3.2f Analysis of variance (ANOVA analysis): Analysis of variance is employed to identify the influence or contribution of each of the process parameters on the multi-response FSSW process. Either $F$-value, $P$-value or percentage contribution (estimated from SS-sum of square) can be directly utilized to examine the contribution of welding parameters on the resultant multi-response GRG. Table 14 shows the analysis of variance of the selected welding parameters on the resultant GRG. Based on the ANOVA table, the most significant parameter appears to be the tool rotational speed with $48.42 \%$ contribution. This is followed by the plunge depth with a contribution of about $39.54 \%$. Meanwhile, according to the

\section{Main Effects Plot for GRG}

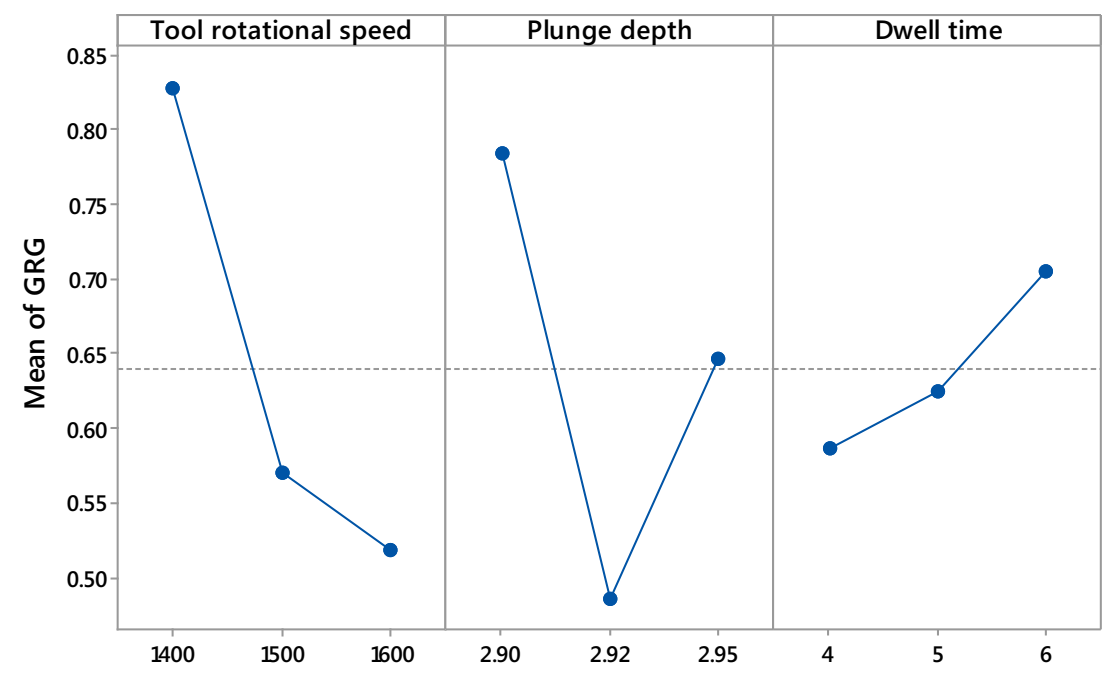

Figure 5. Main effect plot of Grey relational grade. 
Table 14. ANOVA table for the GRG.

\begin{tabular}{lccccccc}
\hline Source & DF & Seq SS & Adj SS & Adj MS & $F$-value & $P$-value & Contribution $(\%)$ \\
\hline Rotational speed & 2 & 0.16386 & 0.16386 & 0.081930 & 8.80 & 0.102 & 48.42 \\
Plunge depth & 2 & 0.13381 & 0.13381 & 0.066905 & 7.19 & 0.122 & 0.457 \\
Dwell time & 2 & 0.02213 & 0.02213 & 0.011065 & 1.19 & 6.54 \\
Error & 2 & 0.01862 & 0.01862 & 0.009308 & & & \\
Total & 8 & 0.33842 & & & & & \\
\hline
\end{tabular}

$S=0.0964793 ; R^{2}=94.50 \% ; R^{2}(\operatorname{adj})=78.00 \%$.

Table 15. Confirmation test.

\begin{tabular}{lccc}
\hline & $\begin{array}{c}\text { Initial } \\
\text { welding }\end{array}$ & $\begin{array}{c}\text { Optimal } \\
\text { experiment }\end{array}$ & $\begin{array}{c}\text { Improvement } \\
(\%)\end{array}$ \\
\hline Parameter level & $A_{2} B_{3} C_{1}$ & $A_{1} B_{1} C_{3}$ & \\
Failure load (N) & 1816 & 2313 & 27 \\
$\begin{array}{c}\text { Expelled flash } \\
\text { volume }\left(\mathrm{mm}^{3}\right)\end{array}$ & 31.23 & 22.48 & 28 \\
$\begin{array}{c}\text { Effective bonded } \\
\text { size }(\mathrm{mm})\end{array}$ & 0.54 & 0.66 & 22 \\
\hline
\end{tabular}

$10 \%$ rule suggested by Roy [35], a parameter is adjudged to be insignificant when it has a less than $10 \%$ influence $[17,35]$. As a result, it can be inferred that dwell time does not have a significant influence on the resultant combination of the weld responses.

3.2g Confirmation test/validation of result: The optimal result is validated by conducting experimental sets at optimal parameter combination of $A_{1}, B_{1}$ and $C_{3}$ (1400 rpm, $2.90 \mathrm{~mm}$ and $6 \mathrm{~s}$ ). Thus, table 15 shows the obtained validation result and the improvements of weld responses at the optimal setting. As a result, the hybrid TM-GRA-PCA optimization approach was efficient in improving FL and EBS of welds by $27 \%$ and $22 \%$, respectively. Equally, the EFV was reduced by $28 \%$.

\subsection{Fracture analysis of welds}

The close-up scanning electron micrographs of fracture surfaces reveal three critical zones in each of the examined conical pin welded joints. The critical zones in failed conical pin welded joints are contact and rotationally impelled unbonded zone (Zone I), interfacial/cleavage failure zone (Zone II) and circumferential nugget shear failure zone (Zone III). The fracture surfaces of the weld are shown in figure 6, and the respective critical zones (IIII) are marked on the fracture surfaces.

Zone I (contact and rotationally impelled unbonded zone) is the interfacial region (at the faying area between the upper and the lower sheets) underneath the outer circumferential edge of the shoulder surface. It shows contact and rotational marks induced on the faying interfacial surface by the axial pressure and rotational action of the welding tool. As a result, no significant inter-material flow or intermingling of plasticized material of the upper and lower plate ensues in this zone. Therefore, there is no salient damage or little dimple-like structure on the surface of this zone.

Zone II is the interfacial/cleavage failure zone of the axially loaded conical pin welded joint. Fracture surface of Zone II is somewhat similar to that of unbonded Zone I, but there are some fracture revelations on the zone. In fact, it is the interfacial region underneath and within the circumferential boundary of the shoulder surface. However, Zone II experiences more tool contact pressure and rotational effect. As a result, inter-material flow occurs between the upper and lower sheets in this zone. Due to the insufficient intermixed material flow at the zone, partial bonding is formed between the upper and lower sheet material and obvious interfacial/cleavage damage with small dimple-like structure is observed in this zone. Therefore, during axial loading condition of the weld, Zone II is at the beginning of fracture failure in conical pin welded joint. In the works of Lin et al [36], this failure mode is referred to as the commencement of necking/ zigzag failure at the interfacially bonded edge between the upper and lower sheets due to extensive plastic deformation of the partially bonded edge. Afterwards, the failure propagates circumferentially into Zone III under axial monotonic loading condition.

Zone III (circumferential nugget shear failure zone) is the region where effective inter-material flow and full bonding occur in conical pin welded joints of the friction stir spot-welded AA2219-O aluminium alloy. The failure growth from Zone II into Zone III and in Zone III, it occurs along the effective weld nugget. As a result, continuous circumferential crack propagation from the hook tip (end of Zone II) through the effective bonded or nugget zone (Zone III) into the keyhole or pin notch emerges as the final weld failure. Likewise, as revealed in the close-up scanning electron micrograph of Zone III (see figure 6), plastic failure of the EBS/nugget zone occurs by shearing or shear localization as circumferential shear stripes or bands are evidenced (continuous lines or stripes indicating a breakthrough of the surface layer). In fact, this corroborates the work of Lin et al [36], which affirms that plastic failure of 


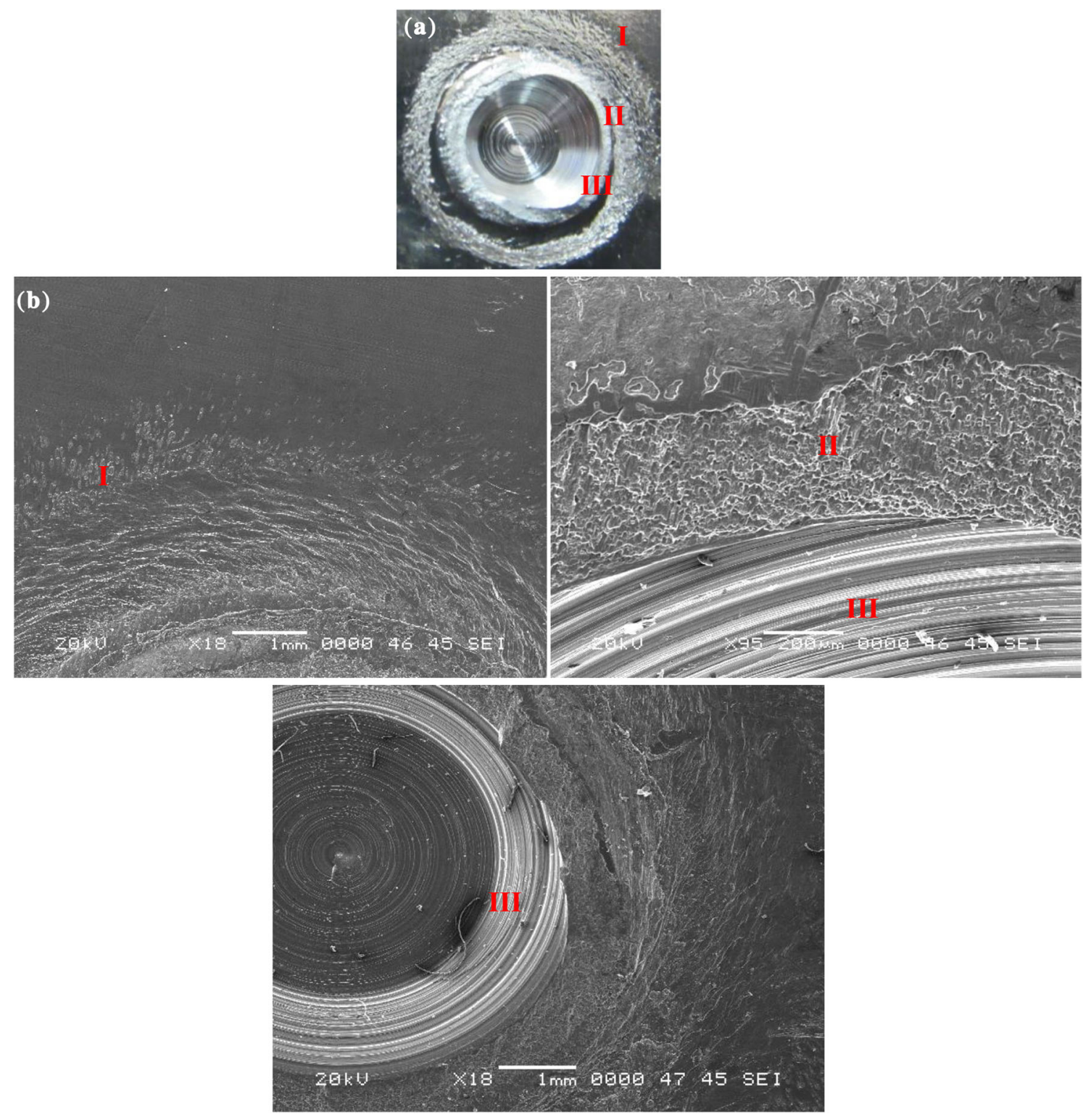

Figure 6. Fracture surface of failed lap shear specimen of conical pin welded joint under monotonic axial condition: (a) plan view of failed lower sheet specimen and (b) close-up scanning electron micrographs of Regions I-III.

concave-tool-welded friction stir spot welds occurs by shear localization.

\section{Conclusions}

The hybrid integration of TM, GRA and PCA has been adopted as a multi-response optimization approach. This hybrid optimization approach has been applied on friction stir spot welds of Alclad AA2219-O alloy by simultaneously considering multiple experimental responses such as FL, EFV and EBS of welds. The following conclusions can be drawn based on the multi-response optimization results:

(1) The hybrid integration of TM, GRA and PCA eliminates subjectivity problem or estimation of GRG based on engineering judgment or assumption. Optimal-weighting values are computed via PCA for the multi-response optimization process.

(2) The multiple responses such as FL, EFV and EBS of welds can be concurrently considered using hybrid integration of TM, GRA and PCA.

(3) The percentage contributions of tool rotational speed and plunge depth on the combined responses are 
$48.42 \%$ and $39.54 \%$, respectively. These parameters influence the examined weld qualities such as FL, EBS and EFV.

(4) The optimum parameter setting for high FL, high EBS and the least EFV is tool rotational speed at level 1 (1400 rpm), plunge depth at level 1 $(2.90 \mathrm{~mm})$ and dwell time at level 3 (6 s).

(5) The embedded Taguchi parametric design into the hybrid multi-response optimization process helps in minimizing the overall cost of experimentation by providing an optimum solution with minimum experimental runs.

(6) The confirmation test validated the use of hybrid multi-response TM-GRA-PCA approach in improving weld quality (reduced ejected flash, maximized FL and bonded size) and optimizing the welding parameters.

(7) The EBS of conical pin welds is limited or reduced by the presence of inevitable hook curve/path. The hook curve divides the stir zone of conical pin welds into two sections which include EBS and ineffective stir zone.

(8) Tool rotational speed, plunge depth and dwell time have significant effects on FL and EBS of conical pin welds. The percentage contributions of tool rotational speed, plunge depth and dwell time on FLs of welds are $53.47 \%, 35.12 \%$ and $10.64 \%$, respectively. Alternatively, the percentage contributions of tool rotational speed, plunge depth and dwell time on EBS of welds are $22.98 \%, 42.68 \%$ and $27.68 \%$, respectively.

(9) Contact and rotationally impelled unbonded zone, interfacial/cleavage failure zone (partially bonded zone) and circumferential nugget shear failure zone (weld nugget zone) are the three critical zones observed on conical pin welded joints.

(10) The eventual failure modes of conical pin welded joints are circumferential nugget shear failure modes. Hook defect greatly influences the fracture mode of conical pin welded joints.

\section{Acknowledgements}

This work was supported by a grant from Scientific Research Project Support-Unit of Kocaeli University (grant no. 2015/71 HD), Turkey. The authors would like to thank Mr. Onur Birbasar of the R\&D Department, Assan Aluminium, Istanbul, Turkey, for his valuable support.

\section{Compliance with ethical standards}

Ethical statement/declaration This work was the expansion of our previous work titled "Understanding the role of welding parameters and tool profile on the morphology and properties of expelled flash of spot welds".

\section{References}

[1] Bozkurt Y 2012 The optimization of friction stir welding process parameters to achieve maximum tensile strength in polyethylene sheets. Mater. Des. 35: 440-445

[2] Ojo O O, Taban E and Kaluc E 2015 Friction stir spot welding of aluminium alloys: a recent review. Mater. Test. 57(7-8): 609-627

[3] Paidar M, Khodabandeh A, Najafi H and Rouh-aghdam A S 2015 An investigation on mechanical and metallurgical properties of 2024-T3 aluminum alloy spot friction welds. Int. J. Adv. Manuf. Technol. 80(1-4): 183-197

[4] Palani K and Elanchezhian C 2015 Multi response optimization of process parameters on AA8011 friction stir welded aluminium alloys using RSM based GRA coupled with DEA. Appl. Mech. Mater. 813-814: 446-450

[5] Taban E, Kaluc E 2007 Comparison between microstructure characteristics and joint performance of 5086-H32 aluminium alloy welded by MIG, TIG and friction stir welding processes. Kov. Mater. Met. Mater. 45(5): 241-248

[6] Vijayan D and Rao V S 2014 A multi-response optimization of tool pin profile on the tensile behaviour of age-hardenable aluminium alloys during friction stir welding. Res. J. Appl. Sci. Eng. Technol. 7(21): 4503-4518

[7] Lakshminarayanan A K and Balasubramanian V 2008 Process parameters optimization for friction stir welding of RDE-40 aluminium alloy using Taguchi technique. Trans. Nonferr. Met. Soc. China 18: 548-554

[8] Oladimeji O O and Taban E 2016 Trend and innovations in laser beam welding of wrought aluminum alloys. Weld. World 60(3): 415-457

[9] Yuvaraj K P and Senthilkumar B 2014 Experimental investigation and optimization of friction stir welding process- $\mathrm{a}$ review. Appl. Mech. Mater. 550: 39-47

[10] Elatharasan G and Kumar V S S 2012 Modelling and optimization of friction stir welding parameters for dissimilar aluminium alloys using RSM. Procedia Eng. 38: 3477-3481

[11] Rambabu G, Naik D B, Rao C H V, Rao K S and Reddy G M 2015 Optimization of friction stir welding parameters for improved corrosion resistance of AA2219 aluminium alloy joints. Def. Technol. 11: 330-337

[12] Mustafa F F, Kadhym A H and Yahya H H 2015 Tool geometries optimization for friction stir welding of AA6061T6 aluminum alloy T-joint using Taguchi method to improve the mechanical behaviour. J. Manuf. Sci. Eng. 137(3): 031018

[13] Dinaharan I and Murugan N 2012 Optimization of friction stir welding process to maximize tensile strength of AA6061/ ZrB2 in-situ composite butt joints. Met. Mater. Int. 18(1): 135-142

[14] Elanchezhian C, Ramnath B V, Venkatesan P, Sathish S, Vignesh T, Siddharth R V, Vinay B and Gopinath K 2014 Parameter optimization of friction stir welding of AA80116062 using mathematical method. Procedia Eng. 97: 775-782

[15] Kesharwani R K, Panda S K and Pal S K 2014 Multi objective optimization of friction stir welding parameters for joining of two dissimilar thin aluminum sheets. Procedia Mater. Sci. 6: 178-187 
[16] Kumar S and Kumar S 2014 Multi-response optimization of process parameters for friction stir welding of joining dissimilar Al alloys by gray relation analysis and Taguchi method. J. Braz. Soc. Mech. Sci. Eng. 37(2): 665-674

[17] Mehat N M, Kamaruddin S and Othman A R 2014 Hybrid integration of Taguchi parametric design, grey relational analysis, and principal component analysis optimization for plastic gear production. Chin. J. Eng. 2014: 1-11

[18] Fung C and Kang P 2005 Multi-response optimization in friction properties of PBT composites using Taguchi method and principal component analysis. J. Mater. Process. Technol. 170: 602-610

[19] Ojo O O, Taban E and Kaluc E 2016 Understanding the role of welding parameters and tool profile on the morphology and properties of expelled flash of spot welds. Mater. Des. 108: 518-528

[20] Shojaeefard M H, Akbari M, Khalkhali A and Asadi P 2014 Optimization of microstructural and mechanical properties of friction stir welding using cellular automation and Taguchi method. Mater. Des. 64: 660-666

[21] Saini S K and Pradhan S K 2014 Optimization of multiobjective response during CNC turning using Taguchi-Fuzzy application. Procedia Eng. 97: 141-149

[22] Raza Z A, Ahmad N and Kamal S 2014 Multi-response optimization of rhamnolipid production using Grey rational analysis in Taguchi method. Biotechnol. Rep. 3: 86-94

[23] Kazancoglu Y, Esme U, Bayramoglu M, Guven O and Ozgun S 2011 Multi-objective optimization of the cutting forces in turning operations using the grey-based Taguchi method. Mater. Technol. 45(2): 105-110

[24] Durairaj M, Sudharsun D and Swamynathan N 2013 Analysis of process parameters in wire EDM with stainless steel using single objective Taguchi method and multi-objective grey relational grade. Procedia Eng. 64: 868-877

[25] Ghosh S, Sahoo P and Sutradhar G 2013 Tribological performance optimization of Al-7.5\% SiCp composites using the Taguchi method and grey relational analysis. J. Compos. 2013: 1-9
[26] Jayaraman P and Kumar L M 2014 Multi-response optimization of machining parameters of turning AA6063 T6 aluminium alloy using Grey relational analysis in Taguchi method. Procedia Eng. 97: 197-204

[27] Reddy V C, Deepthi N and Jayakrishna N 2015 Multi-response optimization of wire EDM on aluminium HE30 by using Grey relational analysis. Mater. Today Proc. 2: 2548-2554

[28] Mustaji M I, Prasetyo T, Ilhamsah H W and Sugiono R S 2015 Optimizing multi-response green machining using Taguchi method based on grey relational analysis. Appl. Mech. Mater. 747: 277-281

[29] Singh H, Kamboj A and Kumar S 2014 Multi-response optimization in drilling Al6063/SiC/15\% metal matrix composite. Int. J. Chem. Nucl. Mater. Metall. Eng. 8(4): 281-286

[30] Jailani H S, Rajadurai A, Mohan B, Kumar A S and Sornakumar T 2009 Multi-response optimisation of sintering parameters of Al-Si alloy-fly ash composite using Taguchi method and grey relational analysis. Int. J. Adv. Manuf. Technol. 45(3-4): 362-369

[31] Bobbili R, Madhu V and Gogia A K Multi-response optimization of wire-EDM process parameters of ballistic grade aluminium alloy. Eng. Sci. Technol. Int. J. 18(4): 720-726

[32] Jolliffe I T 2002 Principal component analysis, 2nd ed. New York: Springer-Verlag Inc

[33] Smith L I 2002 A tutorial on principal components analysis. URL: www.cs.otago.ac.nz/cosc453/student_tutorials/princi pal_components.pdf accessed on 2nd March 2016

[34] Shlens J 2014 A tutorial on principal component analysis. Mountain View, CA: Google Research. URL: http://arxiv. org/pdf/1404.1100.pdf accessed 3rd March 2016

[35] Roy R K 2001 Design of experiment using the Taguchi approach: 16 steps to product and process improvement. New York: John Wiley and Sons

[36] Lin P C, Pin J and Pan T 2008 Failure modes and fatigue life estimations of spot fatigue welds in lap shear specimens of aluminium 6111-T4 sheets. Part 1: welds made by a concave tool. Int. J. Fatigue 30(1): 74-89 